Hückel covers a very large field in describing generally not only the structure of organic molecules but also much of the work on reactivity, rearrangements and the like. Stereochemistry gets a whole chapter to itself. F. Seel contributes a chapter on the triphenyl methyl type of free radicals and discusses in some detail those molecules which can exist as di-radicals. Hückel concludes the volume with a chapter on substitution, addition reactions and rearrangements.

The second volume deals with dipole moments and the relationship between physical properties and molecular constitution. G. Scheibe writes on the absorption spectra of conjugated compounds, and $\mathrm{J}$. Goubeau on Raman spectra, while G. V. Schulz finishes off with a chapter on the mechanism of addition polymerizations - a section where there has been a complete transformation since the end of the War. Reading through the volumes as a whole, it is surprising to find how much pure science was, in fact, done in Germany during the War. It is equally surprising that during that period the authors appeared to be unaware of what was going on in other countries, presumably owing to lack of current literature. It is very difficult to write scientific history of this kind, especially as the author now knows of recent developments; and it is therefore natural to find in many places, not only in footnotes but also in the text, references to more recent work so that the author may continue the discussion and bring it more in line with up-to-date ideas. Even though it is necessarily a one-sided effort, the ideas, the method of approach and the arguments provide a fruitful ground for further thought and further development.

The translation in many parts is not well done, and some of the terms are translated into English which would be quite unintelligible to anyone except an expert in the field. Sometimes in the theoretical section the translation is so literal that it is again difficult to follow the line of argument. The volume is litho-printed, which is not as satisfactory as the conventional method of reproduction ; but presumably the main excuse is that the cost of production must be kept down to an absolute minimum.

H. W. Melville

\section{FRESHWATER ALGÆ}

Algae of the Western Great Lakes Area, exclusive of Desmids and Diatoms

By G. W. Prescott. (Bulletin No. 31.) Pp. xiii +946. (Bloomfield Hills, Mich. : Cranbrook Institute of Science, 1951.) 10.50 dollars.

7 HE Great Lakes region of North America with its great variety of lakes, swamps and marshes is an especially suitable location for the intensive study of freshwater algæ. In this book, G. W. Prescott has paid particular attention to the diversity of geological formation in the region, with the consequent variety in soil types and in algal distribution. The relationships of the phytoplankton to the productivity of the lakes is discussed, and this section of the book concludes with a summary of the factors that appear to determine the character of lake floras.

Throughout the volume the term algæ has been used in its wide sense, the Euglenophyta and Pyrrophyta being included. Desmids and diatoms have not been described, the former because their great variety is thought to merit special treatment and the latter because they are being studied intensively in the area by another worker.

The varied habitats found in the Michigan and Wisconsin lakes result in a rich algal flora of some thirteen hundred species. The author has attempted to make the list as complete as possible, and therefore records of earlier workers, including those of Gilbert M. Smith's planktonic surveys of Wisconsin lakes, have been included. It would not have been possible in one volume to give a complete description of all the species mentioned; but keys to orders, families, genera and species in each class are followed by notes on the important taxonomic characteristics of each species and by a brief description of reproductive structures where these are of diagnostic importance.

The taxonomic section of the book concludes with a general analytical key to the genera which should prove of value to students, conservators of fresh water, and those less familiar with the classification of the algæ, who might not have the basic knowledge to find their way among the ramifications of the groups in the text. A glossary of technical terms follows, together with a comprehensive bibliography in which the more important works and also those dealing especially with Michigan and Wisconsin algæ are differentiated. The drawings in the one hundred and thirty-six plates are bold and clear they will be of great use for purposes of identification.

The book will be of value over much of the northern hemisphere, because of the wide distribution of many of the species, and Mr. Prescott is to be congratulated on its clarity and general usefulness. For the benefit of those who are less familiar than the author with the geography of the area, a general map would have been helpful, even if it had been incorporated in the form of end-papers. It would have had especial value if some indication of the geology of the region as well as its physical features could have been outlined.

LILY NEWTON

\section{CLOWDER OF CATS}

Catalogue of the Genus Felis

By R. I. Pocock. Pp. viit 190. (London: British Museum (Natural History), 1951.) 30s.

$\mathrm{A}^{\mathrm{T}}$ $T$ the time of his death in 1947 at the age of eighty-four, the late R. T. Pocock was preparing a systematic monograph of the Felidx; more than once towards the end of his life he had remarked to his friends that he was quite ready to depart, but that he hoped he would be spared to complete "his cats". But it was such an immense task that, although active and working to the end, he was unable to win his race against time. Nevertheless, part of the work was left in a tolerably complete state, and the present volume, dealing with the genera Felis and Otocolobus, contains all that was ready for publication.

The patient and painstaking care that the author brought to the difficult work of arranging a great number of geographical races in systematic order, and of disentangling the chaotic synonymy, are emphasized by the fact that this catalogue deals with only eight species, seven of them in the genus Felis, which are, however, divided into no less than fiftytwo named subspecies and three without names. More detailed attention than is customary has been 
given to individual skins and skulls because this was the "only means of emphasizing the extent of the individual variations in colour, shape of skull or teeth to which the species or local races are liable". This is fully justified by the careful analysis of the subspecific characters of each race, and zoologists will heartily agree with the author's statement that "realisation of this [variation] is particularly called for in view of the prevalent tendency to regard as deserving of nominal distinction perhaps single specimens differing from one another in trivial characters if inhabiting different localities".

The catalogue starts with a discussion of the characters and subdivisions of the family Felidæ and then deals with each species and subspecies, going fully into the geographical distribution, diagnosis, and skin and skull characters, with numerous tables of measurements and some figures of skulls. The specimens in the collection of the British Museum (Natural History) are listed at the end of each article; but the book is more than a catalogue, for the subspecies not represented in the collections are discussed as fully as the others.

Any species of animal occupying a very extensive range of territory that includes many different kinds of habitat inevitably becomes differentiated into subspecies, and this is well shown by the many races of Felis lybica the range of which covers part of southern Europe, the whole of Africa except the thickly 1orested area, and extends through Arabia and Palestine to northern India and Turkestan. Pocock recognizes twenty-five named subspecies of this cat, and describes three other forms that he regards as separable from the others, though he does not venture to name them. The same phenomenon is illustrated on a smaller scale by $F$. chaus with eight subspecies, and by $F$. silvestris with seven.

A very interesting and unusual section treats of $F$. catus, the domestic cat, a composite form of which the European representatives at least owe their origin to the crossing of two wild species, $F$. silvestris and $F$. lybica. This is a subject to which Pocock had devoted much study and on which he had previously published papers. The tabby pattern of the domestic cat is dimorphic : in the form torquata, the 'striped tabby', the pattern consists of comparatively narrow vertical stripes on the sides of the body ; in the typical catus form, the 'blotched tabby', the broad stripes on the sides show a looped or spiral arrangement and three dorsal stripes run to the root of the tail. The two forms are individually variable; but one or the other can usually be detected in the majority of domestic cats, though the stripes on the body may be entirely suppressed in the torquata phase which, Pocock considers, is less stable than the catus phase. Pocock does not agree with Schwarz's suggestion that the name $F$. catus should be extended to include the two wild species $F$. silvestris and $F$. lybica as well as all the domestic breeds, because, while admitting the obvious kinship between the last two, he finds no evidence that they intergrade in the wild state. He gives it as his opinion that the torquata form of the domestic cat originates from the hybridization of $F$. silvestris and $\vec{F}$. lybica, and that the catus form arose as a mutation from torquata. But the whole question of the domestic races is complicated by the widespread occurrence of feral animals that have interbred with the various sub. species of one or the other of the supposed parent species, and perhaps with others; the author discusses these at some length and gives a tolerably full description of feral specimens from all parts of the world.

It is a matter for regret that Pocock did not live to finish his great work or to receive the congratulations of his friends on this valuable instalment. The book is uniform with the new style of Museum catalogues which in format and typography leave nothing to be desired.

\section{THE GREENSHANK}

The Greenshank

By Desmond Nethersole-Thompson. (New Naturalist Series.) Pp. xii $+244+28$ plates. (London and Glasgow : Wm. Collins, Sons and Co., Ltd., 1951.) 15s. net.

CHIS is a remarkable book, and could have been written by no other person than Mr. Desmond Nethersole-Thompson, who has studied the greenshank more closely than any other naturalist. The secret of the book's success is revealed on p. 98 : "Year after year, from late March onwards, our whole lives [the author here refers to his wife, who is at least as skilled an observer as he is] were dedicated to the greenshanks". The author has the good fortune to live in greenshank country, and, as he shows in his book, he has a great love for this bird of the wonderful courtship flight and glorious song. $\mathrm{Mr}$. Nethersole-Thompson is par excellence a field naturalist, and many of his observations are entirely new. $\mathrm{He}$ is also a good writer, and some of his passages describing the greenshank in its Highland home will linger in one's memory. The reader follows the fortunes of the greenshank from the arrival of the male (who precedes the female at the nesting grounds) through the courting period, and then watches with the author the hatching of the young, the disposal of the egg-shells, and the broods in the pine forests until they fly south in late summer.

A good deal of the book is naturally devoted to the greenshank's song. This is one of the most remarkable - one might perhaps say the most remarkable-of British bird songs. I can bear out the author when he says that the singing bird sometimes flies so high in song that he enters the cloud canopy. One has to watch the greenshank long and closely to hear the full song, which continues without pause minute after minute, the singer all the time flying high in the air, in wide circles, at his topmost speed. It is one of the songs that a great lover and student of birds, Viscount Grey of Fallodon, had long wished to hear and never heard.

There are so many good things in this book that I find it hard to single out any particular part of it for special praise. I can truly say that, as the greenshank has always been a close friend of mine, I should be critical of any book on this species, and it is therefore my tribute that $X$ have nothing but praise for one of the outstanding volumes in the "Now Naturalist" series. No bird lover, or bird student, can afford to be without this book, which is superbly illustrated from the photographs taken by a number of leading Nature photographers, who have often been helped by the author. It was, by the way, through his help that Dr. Ludwig Koch was able to obtain recordings of the greenshank's song, and of the hatching calls at the nest, made by parents and young.

SETON GORDON 